\title{
MODEL COX EXTENDED UNTUK MENGATASI NONPROPORTIONAL HAZARD PADA KEJADIAN BERSAMA
}

\author{
Anita Nur Vitriana ${ }^{\mathrm{a}}$, Rosita Kusumawati ${ }^{\mathrm{b}}$ \\ ${ }^{a}$ Program Studi Matematika FMIPA UNY \\ Jl. Colombo No.1 Yogyakarta, anitavtrn@gmail.com \\ ${ }^{\mathrm{b}}$ Program Studi Matematika FMIPA UNY \\ Jl. Colombo No.1 Yogyakarta, rosita.kusumawati@gmail.com
}

\begin{abstract}
ABSTRAK
Model Cox extended merupakan modifikasi dari model Cox proportional hazard ketika asumsi proportional hazard tidak dipenuhi. Penelitian ini bertujuan untuk menjelaskan prosedur pembentukan model Cox extended pada kejadian bersama dan penerapannya pada kasus individu berhenti bekerja. Estimasi parameter pada model Cox extended menggunakan maximum partial likelihood estimation (MPLE) dan pendekatan metode Breslow untuk mengatasi kejadian bersama. Data yang digunakan adalah data berhenti bekerja dari 201 individu dengan 4 variabel bebas, yaitu jenis kelamin, umur, status pernikahan dan pendidikan terakhir. Dari hasil perhitungan dengan bantuan software $\mathrm{R}$ 3.1.2, diperoleh model Cox extended dengan fungsi waktu $g(t)=t$ adalah model terbaik dengan hasil variabel yang berpengaruh signifikan, yaitu umur, status pernikahan, umur terikat waktu dan status pernikahan terikat waktu, dimana setiap penambahan umur 1 tahun menurunkan risiko individu berhenti bekerja sebesar 0,9 kali dan setiap individu yang sudah menikah memiliki risiko berhenti bekerja 0,55 kali lebih kecil daripada yang belum menikah.
\end{abstract}

Kata Kunci: model Cox proprotional hazard, model Cox extended, maximum partial likelihood estimation, kejadian bersama, metode Breslow

\begin{abstract}
The extended Cox model is a modification of the Cox proportional hazards model when the proportional hazards assumption is not satisfied. The aims of this study are to explain the extended Cox model building procedure for ties and to apply the model job stopped case. Estimation of parameters in the extended Cox model is using the Maximum Partial Likelihood Estimation (MPLE) and the Breslow method approach to overcome ties events. The data used in this study is the job stopped data which contains 201 individuals with 4 independent variables, i.e. gender, age, marital status and highest education. From the analysis with R 3.1.2 software, it is obtained that an extended Cox model with $\mathrm{g}(\mathrm{t})=\mathrm{t}$ function time is the best model and the significant variables are age, marital status, time-dependent age, time-dependent marital status. The increasing of age will reduce the individual's retiring risks 0.9 times, while married people will have risk to leave their job 0.55 times smaller than single people.
\end{abstract}

Keywords: the Cox proportional hazards model, maximum partial likelihood estimation, AIC, the extended Cox model, ties, Breslow method 


\section{Pendahuluan}

Analisis survival atau analisis data ketahanan hidup adalah suatu metode statistik untuk menganalisis data dengan variabel terikat yang diperhatikan berupa waktu sampai terjadinya suatu kejadian (Kleinbaum dan Klein 2012). Salah satu tujuan analisis survival adalah mengetahui hubungan antara waktu survival dengan variabel-variabel yang diduga mempengaruhi waktu survival. Hubungan tersebut dapat dimodelkan dengan model regresi Cox proportional hazard, yang mempunyai variabel terikat berupa waktu survival dan variabel bebas berupa variabel yang diduga berpengaruh terhadap waktu survival.

Penggunaan model regresi Cox proportional hazard harus memenuhi asumsi proportional hazard, berarti juga bahwa perbandingan antara fungsi hazard individu satu dengan fungsi hazard individu yang lain (hazard ratio) harus konstan dari waktu ke waktu. Jika asumsi ini tidak terpenuhi, maka model dikatakan nonproportional hazard (Kleinbaum dan Klein 2012). Salah satu perluasan model Cox yang memperhatikan pelanggaran asumsi proportional hazard adalah model Cox extended. Model Cox extended merupakan perluasan dari model Cox proportional hazard, yaitu perkalian dari variabel bebas yang tidak memenuhi asumsi proportional hazard dengan fungsi waktu. Fungsi waktu yang dapat digunakan, antara lain $g(t)=0, g(t)=$ $t, g(t)=\log t$, dan fungsi heaviside.

Beberapa artikel yang mengkaji tentang model Cox extended telah ditulis oleh beberapa orang, antara lain Ata dan Sozer (2007) yang membahas model regresi Cox untuk mengatasi nonproportional hazard yang diterapkan pada data survival kanker paru-paru. Model Cox extended untuk mengatasi nonproportional hazard juga telah ditulis oleh Agnesia (2014) yang membahas perbandingan model Cox extended dan model Cox stratifikasi pada data ketahanan hidup penderita kanker leher rahim dan penderita hipertensi dengan terapi tablet Captopril.

Pada data waktu survival sering terdapat kejadian bersama, yaitu keadaan dimana terdapat dua individu atau lebih yang mengalami kejadian pada waktu bersamaan atau disebut ties. Pada model Cox proportional hazard tidak boleh terjadi ties karena akan menimbulkan masalah pada pembentukan maximum partial likelihood (Xin 2011). Ada beberapa pendekatan yang dapat digunakan untuk mengatasi terjadinya ties, yaitu metode Efron, metode Breslow dan metode Exact. 
Mengingat kebaikan model Cox extended untuk mengatasi nonproportional hazard, peneliti tertarik untuk mempelajari model Cox extended dengan metode Breslow pada kejadian bersama yang tidak memenuhi asumsi proportional hazard dan menerapkannya. Penulis menggunakan data berhenti bekerja pada German Life History Studi (Blossfeld dan Rohwer 2002) yang mengandung kejadian bersama dan tidak memenuhi asumsi proportional hazard.

\section{Metode Penelitian}

Peneliti tertarik untuk mempelajari model Cox extended dengan metode Breslow dan menerapkannya pada data survival yang memuat kejadian bersama dan tidak memenuhi asumsi proportional hazard, yaitu data individu berhenti bekerja (Blossfeld dan Rohwer 2002). Data penelitian ini berisi waktu individu berhenti bekerja dengan 208 individu, tetapi ada 7 individu yang tidak dapat diamati secara lengkap sehingga hanya ada 201 individu yang dapat diamati. Dari 201 individu, ada beberapa yang berhenti bekerja lebih dari satu kali sehingga diperoleh $n=600$ dan terdapat 4 variabel bebas, yaitu jenis kelamin, umur, status pernikahan dan pendidikan terakhir.

Sebelum pembentukan model Cox extended, akan dijelaskan pembentukan model Cox proportional hazard pada kejadian bersama. Langkah-langkah dalam pembentukan model Cox proportional hazard pada kejadian bersama antara lain; (1) identifikasi data, (2) pendugaan parameter model regresi Cox proportional hazard dengan metode Breslow, (3) pengujian parameter pada model regresi Cox proportional hazard dengan uji Wald, (4) pengujian asumsi proportional hazard.

Setelah dilakukan uji asumsi pada model Cox proportional hazard pada kejadian bersama, diketahui variabel yang memenuhi asumsi proportional hazard atau tidak. Jika terdapat variabel yang tidak memenuhi asumsi proportional hazard, diperlukan model baru yaitu model Cox extended pada kejadian bersama. Langkah-langkah pembentukan model extended untuk mengatasi nonproportional hazard pada kejadian bersama antara lain; (1) penambahan fungsi waktu $g(t)$ pada variabel yang tidak memenuhi asumsi proportional hazard, (2) pendugaan parameter model Cox extended dengan metode Breslow, (3) pengujian parameter model Cox extended, (4) perbandingan nilai Akaike's Information Criterion (AIC) pada masingmasing model, dan (5) interpretasi hazard ratio pada model Cox extended. 


\section{Hasil dan Pembahasan}

Sebelum pembentukan model Cox extended, terlebih dahulu akan dilakukan pembentukan model Cox proportional hazard.

\section{Pembentukan Model Cox Proportional} Hazard

Pembentukan model Cox proportional hazard dilakukan untuk mengetahui hubungan antara waktu survival dengan variabel-variabel yang diduga mempengaruhi waktu survival.

\section{Pendugaan Parameter}

Estimasi parameter model Cox proportional hazard menggunakan pendekatan metode Breslow untuk mengatasi kejadian bersama dengan bantuan software R 3.1.2 sebagai berikut:

Tabel 1. Estimasi Parameter Model Cox Proportional Hazard dengan metode Breslow

\begin{tabular}{lccc}
\hline Variabel & $\begin{array}{c}\text { Koefisie } \\
\mathrm{n}\end{array}$ & $\exp \left(\beta_{j}\right)$ & $\mathrm{SE}$ \\
\hline Jenis & 0,08405 & $\begin{array}{c}1,0876 \\
9\end{array}$ & $\begin{array}{c}0,0972 \\
0\end{array}$ \\
Kelamin & & 0,8629 & 0,0097 \\
Umur & $-0,14743$ & 2 & 9 \\
Status & & 0,7527 & 0,1093 \\
Pernikaha & $-0,28405$ & 3 & 1 \\
n & & 1,1091 & 0,0208 \\
Pendidika & 0,10356 & 1 & 4 \\
n Terakhir & & & \\
\hline
\end{tabular}

Dari Tabel 1 diperoleh persamaan model Cox proportional hazard, sebagai berikut:

$$
\begin{gathered}
h_{i}\left(t_{i}\right)=h_{0}(t) \exp \left(0,08405 X_{1}\right. \\
-0,14743 X_{2} \\
\left.-0,28405 X_{3}+0,10356 X_{4}\right)
\end{gathered}
$$

Selanjutnya dilakukan uji log partial likelihood ratio, dengan bantuan software $\mathrm{R}$ 3.1.2 diperoleh $\ln L(0)=-2.583,436$ dan $\ln L(\hat{\beta})=-2.336,730 \quad$ sehingga diperoleh hasil yaitu $G=493,412 \geq$ $\chi_{(0,05 ; 4)}^{2}$ dengan $\chi_{(0,05 ; 4)}^{2}=9,48772$, maka $H_{0}$ ditolak dan dapat disimpulkan bahwa paling sedikit ada satu variabel yang berpengaruh dalam model.

\section{Pengujian Parameter}

Hasil pengujian parameter secara parsial menggunakan uji Wald dengan bantuan software R 3.1.2 yaitu sebagai berikut.

Tabel 2. Hasil Pengujian Parameter secara Parsial dengan Uji Wald menggunakan Metode Breslow

\begin{tabular}{lccc}
\hline Variabel & Koefisien & SE & $z_{\text {hitung }}^{2}$ \\
\hline Jenis & 0,41560 & 0,0948 & 19,215 \\
Kelamin & & 1 & 1 \\
Umur & $-0,14849$ & 0,0086 & 297,66 \\
Status & & & 7 \\
Pernikaha & $-1,2365$ & 0,0980 & 159,19 \\
n & & & 7 \\
Pendidika & 0,004401 & 0,0212 & 0,0426 \\
n Terakhir & & 9 & 9 \\
\hline
\end{tabular}

Dari Tabel 2 diperoleh bahwa variabel jenis kelamin, umur, dan status pernikahan 
berpengaruh terhadap waktu survival, sedangkan variabel pendidikan terakhir tidak berpengaruh terhadap waktu survival dengan $z^{2}=0,04269<\chi_{0,05 ; 1}^{2}=3,841$, maka variabel pendidikan terakhir dikeluarkan dari model, sehingga diperoleh:

Tabel 3. Estimasi Parameter Model Cox Proportional Hazard dengan metode Breslow pada Variabel yang Berpengaruh Signifikan

\begin{tabular}{lccc}
\hline Variabel & $\begin{array}{c}\text { Koefisie } \\
\mathrm{n}\end{array}$ & $\exp \left(\beta_{j}\right)$ & $\mathrm{SE}$ \\
\hline $\begin{array}{l}\text { Jenis } \\
\text { Kelamin }\end{array}$ & 0,01785 & $\begin{array}{c}1,0180 \\
1\end{array}$ & $\begin{array}{c}0,0965 \\
8\end{array}$ \\
Umur & $-0,13840$ & $\begin{array}{c}0,8707 \\
5\end{array}$ & $\begin{array}{c}0,0094 \\
7\end{array}$ \\
$\begin{array}{l}\text { Status } \\
\begin{array}{l}\text { Pernikah } \\
\text { an }\end{array}\end{array}$ & $-0,27929$ & $\begin{array}{c}0,7563 \\
2\end{array}$ & $\begin{array}{c}0,1106 \\
8\end{array}$ \\
\hline
\end{tabular}

Dari Tabel 3 diperoleh persamaan model Cox proportional hazard pada variabel yang signifikan berpengaruh adalah:

$$
\begin{gathered}
h_{i}\left(t_{i}\right)=h_{0}(t) \exp \left(0,01785 X_{1}\right. \\
-0,13840 X_{2} \\
\left.-0,27929 X_{3}\right)
\end{gathered}
$$

\section{Pengujian Asumsi Proportional Hazard}

Pengujian asumsi proportional hazard pada penelitian ini menggunakan plot log-minus-log survival dan residual Schoenfeld.

\section{a. Plot Log-Minus-Log Survival}

Berdasarkan pengujian asumsi menggunakan plot log-minus-log survival pada Gambar 1, 2, dan 3 diperoleh hasil bahwa variabel jenis kelamin, umur, dan status pernikahan memenuhi asumsi proportional hazard karena dari ketiga plot tersebut tidak berpotongan dan mendekati paralel.

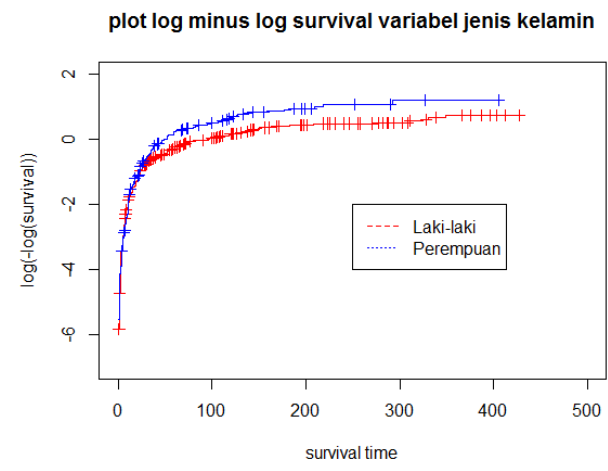

Gambar 1. Plot Log-Minus-Log Survival pada Variabel Jenis Kelamin

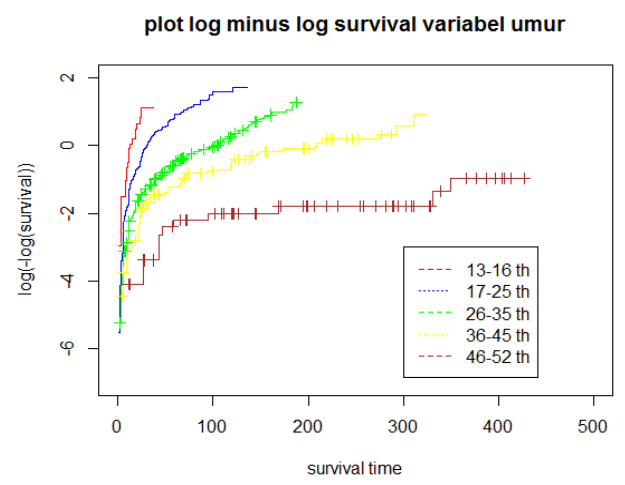

Gambar 2. Plot Log-Minus-Log Survival pada Variabel Umur 


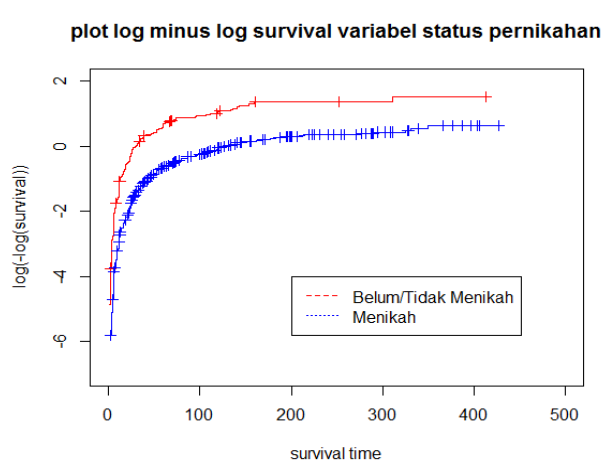

Gambar 3. Plot Log-Minus-Log Survival pada Variabel Status Pernikahan

\section{b. Residual Schoenfeld}

Berikut pengujian asumsi dengan residual Schoenfeld pada variabel bebas dengan bantuan software R 3.1.2, yaitu:

Tabel 4. Korelasi, $\chi_{\text {hit }}^{2}$ dan $p$-value Variabel Bebas

\begin{tabular}{lccc}
\hline Variabel & Korelasi & $\chi_{\text {hit }}^{2}$ & $p$-value \\
\hline Jenis & 0,0386 & 0,715 & 0,39795 \\
Kelamin & $-0,1071$ & 7,330 & 0,00678 \\
Umur & 0,1127 & 5,454 & 0,01953 \\
Status & Pernikahan & & \\
\hline
\end{tabular}

Dari Tabel 4 diperoleh bahwa variabel jenis kelamin memenuhi asumsi proportional hazard, sedangkan variabel umur tidak memenuhi asumsi proportional hazard, dengan p-value $=0,00678<\alpha=0,05$ dan variabel status pernikahan juga tidak memenuhi asumsi proportional hazard, dengan $p$ value $=0,01953<\alpha=0,05$.

Berdasarkan pengujian dengan plot log-minus-log dan residual Schoenfeld diperoleh kesimpulan bahwa variabel umur dan status pernikahan tidak memenuhi asumsi proportional hazard.

\section{Model Cox Extended}

Persamaan model Cox extended pada variabel umur $\left(X_{2}\right)$ dan status pernikahan $\left(X_{3}\right)$, yaitu sebagai berikut:

$$
\begin{array}{r}
h(t, X)=h_{0}(t) \exp \left[\beta_{1} X_{1}+\beta_{2} X_{2}+\beta_{3} X_{3}\right. \\
\left.+\delta_{2} X_{2} g(t)+\delta_{3} X_{3} g(t)\right]
\end{array}
$$

a. Model Cox Extended dengan Fungsi

Waktu $g(t)=t$

\section{1) Pendugaan Parameter}

Estimasi parameter model Cox extended dengan $g(t)=t$ menggunakan metode Breslow dengan bantuan software $\mathrm{R}$ 3.1.2, yaitu sebagai berikut.

Tabel 5. Estimasi Parameter Model Cox Extended dengan $g(t)=t$ menggunakan Metode Breslow

\begin{tabular}{lccc}
\hline Variabel & $\begin{array}{c}\text { Koefisi } \\
\text { en }\end{array}$ & $\exp \left(\beta_{j}\right)$ & SE \\
\hline Jenis & 0,02396 & 1,0243 & 0,0965 \\
Kelamin & - & 9 & 4 \\
Umur & - & 0,9052 & 0,0133 \\
Umur & 0,09953 & 7 & 5 \\
$g(t)$ & - & 0,9992 & 0,0001 \\
Status & 0,00071 & 9 & 9 \\
Pernikah & - & 0,5418 & 0,1693 \\
an & 0,61269 & 9 & 5 \\
Status & & & \\
Pernikah & 0,00618 & 1,0062 & 0,0027 \\
an $g(t)$ & & 1 & 5 \\
\hline
\end{tabular}


Dari Tabel 5 diperoleh persamaan model Cox extended dengan $g(t)=t$, sebagai berikut:

$$
\begin{gathered}
h_{i}\left(t_{i}\right)=h_{0}(t) \exp \left(0,02396 X_{1}\right. \\
-0,09953 X_{2} \\
-0,61269 X_{3}-0,00071 X_{2} g(t) \\
\left.+0,00618 X_{3} g(t)\right)
\end{gathered}
$$

Selanjutnya dilakukan uji $\log$ partial likelihood ratio, dengan bantuan software R 3.1.2 diperoleh $\ln L(\hat{\beta})=$ $-2.347,311$ dan $\quad \ln L(\hat{\delta})=$ $-2.339,316$ sehingga diperoleh hasil yaitu $G=15,99>\chi_{(0,05 ; 2)}^{2}$ dengan $\chi_{(0,05 ; 2)}^{2}=5,991$, maka $H_{0}$ ditolak dan dapat disimpulkan bahwa paling sedikit ada satu variabel yang berpengaruh dalam model.

\section{2) Pengujian Parameter}

Hasil pengujian parameter secara parsial menggunakan uji Wald dengan bantuan software R 3.1.2 yaitu sebagai berikut:

Tabel 6. Hasil Pengujian Parameter secara Parsial dengan Uji Wald untuk

\begin{tabular}{|c|c|c|c|}
\hline Variabel & $\begin{array}{c}\text { Koefisi } \\
\text { en }\end{array}$ & SE & $z_{\text {hitung }}^{2}$ \\
\hline $\begin{array}{l}\text { Umur } \\
g(t)\end{array}$ & $\begin{array}{c}0,0022 \\
1\end{array}$ & $\begin{array}{c}0,0001 \\
6\end{array}$ & $\begin{array}{c}187,48 \\
3\end{array}$ \\
\hline $\begin{array}{l}\text { Status } \\
\text { Pernikah } \\
\text { an } g(t)\end{array}$ & $\begin{array}{c}- \\
0,0099 \\
2\end{array}$ & $\begin{array}{c}0,0014 \\
3\end{array}$ & 48,065 \\
\hline
\end{tabular}

Model Cox Extended dengan $g(t)=t$ menggunakan Metode Breslow
Dari Tabel 6 diperoleh bahwa variabel umur terikat waktu berpengaruh terhadap waktu survival dengan $\quad z^{2}=187,483>\chi_{0,05 ; 1}^{2}=$ 3,841 , dan variabel status pernikahan terikat waktu berpengaruh terhadap waktu survival dengan $z^{2}=$ $48,065>\chi_{0,05 ; 1}^{2}=3,841$.

\section{b. Model Cox Extended dengan Fungsi} Waktu $g(t)=\log t$

\section{1) Pendugaan Parameter}

Estimasi parameter model Cox extended dengan $g(t)=\log t$ menggunakan metode Breslow dengan bantuan software R 3.1.2, yaitu sebagai berikut.

Tabel 7. Estimasi Parameter Model Cox Extended dengan $g(t)=\log t$ menggunakan Metode Breslow

\begin{tabular}{lccc}
\hline Variabel & $\begin{array}{c}\text { Koefisi } \\
\text { en }\end{array}$ & $\exp \left(\beta_{j}\right)$ & SE \\
\hline Jenis & 0,02213 & 1,0223 & 0,0966 \\
Kelamin & & 8 & 6 \\
Umur & - & 0,9580 & 0,0311 \\
Umur & 0,00428 & 6 & 7 \\
$g(t)$ & - & 0,9738 & 0,0085 \\
Status & 0,02649 & 6 & 8 \\
Pernikah & - & 0,2407 & 0,4425 \\
an & 1,42409 & 2 & 2 \\
Status & & & \\
Pernikah & 0,32162 & 1,3793 & 0,1227 \\
an $g(t)$ & & 5 & 8 \\
\hline
\end{tabular}


Dari Tabel 7 diperoleh persamaan model Cox extended dengan $g(t)=$ $\log t$, sebagai berikut:

$$
\begin{gathered}
h_{i}\left(t_{i}\right)=h_{0}(t) \exp \left(0,02213 X_{1}\right. \\
-0,00428 X_{2} \\
-1,42409 X_{3}-0,02649 X_{2} g(t) \\
\left.+0,32162 X_{3} g(t)\right)
\end{gathered}
$$

likelihood ratio, dengan bantuan software R 3.1.2 diperoleh $\ln L(\hat{\beta})=$ $-2.347,311$ dan $\quad \ln L(\hat{\delta})=$ $-2.341,517$, sehingga diperoleh hasil yaitu $G=11,588>\chi_{(0,05 ; 2)}^{2}$ dengan $\chi_{(0,05 ; 2)}^{2}=5,991$, maka $H_{0}$ ditolak dan dapat disimpulkan bahwa paling sedikit ada satu variabel yang berpengaruh dalam model.

\section{2) Pengujian Parameter}

Hasil pengujian parameter secara parsial menggunakan uji Wald dengan bantuan software R 3.1.2 yaitu sebagai berikut.

Tabel 8. Hasil Pengujian Parameter secara Parsial dengan Uji Wald untuk Model Cox Extended dengan $g(t)=\log t$ menggunakan Metode Breslow

\begin{tabular}{lccc}
\hline Variabel & $\begin{array}{c}\text { Koefisi } \\
\text { en }\end{array}$ & SE & $z_{\text {hitung }}^{2}$ \\
\hline Umur & - & 0,0024 & 287,44 \\
$g(t)$ & 0,04142 & 4 & 3 \\
Status & - & 0,0269 & 136,96 \\
Pernikah & 0,31482 & 0 & 8 \\
an $g(t)$ & & & \\
\hline
\end{tabular}

Dari Tabel 8 diperoleh bahwa variabel umur terikat waktu berpengaruh terhadap waktu survival dengan $z^{2}=287,443>\chi_{(0,05 ; 1)}^{2}=$ 3,841 dan variabel status pernikahan terikat waktu berpengaruh terhadap waktu survival dengan $z^{2}=$ $136,968>\chi_{(0,05 ; 1)}^{2}=3,841$.

\section{c. Model Cox Extended dengan Fungsi Heaviside \\ Pada pembentukan model Cox} extended dengan fungsi heaviside akan dibagi dua interval waktu, dari Gambar 2 dan Gambar 3 peneliti menentukan nilai $t_{0}=36$, maka diperoleh bentuk model Cox extended sebagai berikut:

$$
h(t, X)=h_{0}(t) \exp \left[\beta_{i} X_{i}+\delta_{i} X_{i} g(t)\right]
$$

dengan,

$$
g(t)=\left\{\begin{array}{l}
0, \text { jika } t_{0}<36 \\
1, \text { jika } t_{0} \geq 36
\end{array}\right.
$$

\section{1) Pendugaan Parameter}

Estimasi parameter model Cox extended dengan fungsi heaviside menggunakan metode Breslow dengan bantuan software $\mathrm{R}$ 3.1.2, yaitu sebagai berikut.

Tabel 9. Estimasi Parameter Model Cox Extended dengan heaviside menggunakan Metode Breslow

\begin{tabular}{cccc}
\hline Variabel & $\begin{array}{c}\text { Koefisi } \\
\text { en }\end{array}$ & $\exp \left(\beta_{j}\right)$ & $\mathrm{SE}$ \\
\hline
\end{tabular}




\begin{tabular}{lccc}
\hline Jenis & 0,01943 & 1,0196 & 0,0966 \\
Kelamin & & 2 & 8 \\
Umur & - & 0,8890 & 0,0128 \\
Umur & 0,11766 & 0 & 3 \\
$g(t)$ & - & 0,9615 & 0,0185 \\
Status & 0,03919 & 7 & 9 \\
$\begin{array}{l}\text { Pernikah } \\
\text { an }\end{array}$ & 0,52281 & 5 & 4 \\
$\begin{array}{l}\text { Status } \\
\text { Pernikah } \\
\text { an } g(t)\end{array}$ & 0,48827 & 1,6294 & 0,2266 \\
& & 9 & 9 \\
\hline
\end{tabular}

Dari Tabel 9 diperoleh persamaan model Cox extended dengan fungsi heaviside, sebagai berikut:

$$
\begin{gathered}
h_{i}\left(t_{i}\right)=h_{0}(t) \exp \left(0,01943 X_{1}\right. \\
-0,11766 X_{2} \\
-0,52281 X_{3}-0,03919 X_{2} g(t) \\
\left.+0,48827 X_{3} g(t)\right)
\end{gathered}
$$

Selanjutnya dilakukan uji log partial likelihood ratio, dengan bantuan software R 3.1.2 diperoleh $\ln L(\hat{\beta})=$ $-2.347,311$ dan $\quad \ln L(\hat{\delta})=$ $-2.344,023$ sehingga diperoleh hasil yaitu $G=6,576>\chi_{(0,05 ; 2)}^{2}$ dengan $\chi_{(0,05 ; 2)}^{2}=5,991$, maka $H_{0}$ ditolak dan dapat disimpulkan bahwa paling sedikit ada satu variabel yang berpengaruh dalam model.

\section{2) Pengujian Parameter}

Hasil pengujian parameter secara parsial menggunakan uji Wald dengan bantuan software R 3.1.2 yaitu sebagai berikut.
Tabel 10. Hasil Pengujian Parameter secara Parsial dengan Uji Wald untuk Model Cox Extended dengan fungsi heaviside menggunakan Metode Breslow

\begin{tabular}{lccc}
\hline Variabel & $\begin{array}{c}\text { Koefisi } \\
\text { en }\end{array}$ & SE & $z_{\text {hitung }}^{2}$ \\
\hline Umur & - & 0,0129 & 148,99 \\
$g(t)$ & 0,15807 & 5 & 1 \\
$\begin{array}{l}\text { Status } \\
\text { Pernikah }\end{array}$ & $-0,9208$ & 0,1575 & $\begin{array}{c}34,179 \\
\text { an } g(t)\end{array}$ \\
\hline
\end{tabular}

Dari Tabel 10 diperoleh bahwa variabel umur terikat waktu berpengaruh terhadap waktu survival dengan $z^{2}=148,991>\chi_{(0,05 ; 1)}^{2}=$ 3,841 dan variabel status pernikahan terikat waktu berpengaruh terhadap waktu survival dengan $z^{2}=$ $34,1798>\chi_{(0,05 ; 1)}^{2}=3,841$.

\section{Perbandingan Nilai AIC}

Berikut adalah perbandingan nilai AIC untuk masing-masing model:

Tabel 11. Perbandingan Nilai AIC pada Model

\begin{tabular}{lc}
\hline Model & AIC \\
\hline Model Cox Proportional & $4.700,62$ \\
Hazard & 2 \\
Model Cox Extended dengan & $4.688,63$ \\
$g(t)=t$ & 2 \\
Model Cox Extended dengan & $4.693,03$ \\
$g(t)=\log t$ & 4 \\
Model Cox Extended dengan & $4.698,04$ \\
Fungsi Heaviside & 6 \\
\hline
\end{tabular}


Dari Tabel 11 dapat disimpulkan bahwa model Cox extended dengan $g(t)=t$ adalah model terbaik dalam penelitian ini dengan nilai AIC terkecil yaitu 4.688,632.

\section{Interpretasi Hazard Ratio}

Persamaan model Cox extended dengan $g(t)=t \quad$ menggunakan pendekatan metode Breslow adalah sebagai berikut.

$$
\begin{gathered}
h_{i}\left(t_{i}\right)=h_{0}(t) \exp \left(0,02396 X_{1}\right. \\
-0,09953 X_{2} \\
-0,61269 X_{3}-0,00071 X_{2} g(t) \\
\left.+0,00618 X_{3} g(t)\right)
\end{gathered}
$$

Selanjutnya dilakukan pengujian pada setiap variabel bebas dengan uji Wald dari Tabel 5 untuk mengetahui variabel bebas yang berpengaruh signifikan dalam model Cox extended dengan $g(t)=t$. Diperoleh kesimpulan, yaitu variabel jenis kelamin tidak berpengaruh signifikan terhadap model, $\quad$ dengan $\quad z^{2}=0,06161<$ $\chi_{(0,05 ; 1)}^{2}=3,841$, sedangkan variabel umur, status pernikahan, umur terikat waktu, dan status pernikahan terikat waktu berpengaruh signifikan terhadap model.

Berdasarkan hasil uji Wald, diketahui variabel jenis kelamin tidak berpengaruh dalam model (1), maka variabel tersebut dikeluarkan dari model, sehingga diperoleh persamaan sebagai berikut:

$$
\begin{gathered}
h(t, X(t))=h_{0}(t) \exp \left(-0,09996 X_{2}\right. \\
\left.-0,60896 X_{3}\right) \\
-0,00071 X_{2} g(t)+ \\
0,00618 X_{3} g(t) \quad(2)
\end{gathered}
$$

Selanjutnya dilakukan uji partial likelihood antara model (1) dengan model (2) untuk mengetahui model yang dipilih sebagai model akhir Cox extended. Berdasarkan uji partial likelihood diperoleh $G=0,06<\chi_{(0,05 ; 1)}^{2}$ dengan $\chi_{(0,05 ; 1)}^{2}=3,841 \quad, \quad$ maka dapat disimpulkan bahwa model (2) lebih baik daripada model (1), sehingga model (2) dipilih sebagai model akhir Cox extended.

Pada model (2), nilai $\exp \left(\beta_{i}\right)$ menunjukkan pengaruh variabel terhadap fungsi hazard, yaitu:

1. Setiap penambahan umur 1 tahun, individu memiliki risiko berhenti bekerja yaitu sebesar $\exp (-0,09996+(-0,00071))=$ 0,90423, sehingga setiap penambahan umur 1 tahun akan menurunkan risiko individu berhenti bekerja sebesar 0,9 kali.

2. Setiap individu yang sudah menikah memiliki risiko berhenti bekerja sebesar $\quad \exp (-0,60896+$ $0,00618)=0,54728, \quad$ sehingga 
individu yang sudah menikah memiliki risiko berhenti bekerja lebih kecil daripada individu yang belum menikah yaitu sebesar 0,55 kali.

\section{Kesimpulan}

Prosedur pembentukan model Cox extended untuk mengatasi nonproportional hazard pada kejadian bersama, yaitu (1) penambahan fungsi waktu pada variabel yang tidak memenuhi asumsi proportional hazard, pendugaan parameter pada model Cox extended menggunakan pendekatan metode Breslow untuk kejadian bersama, (3) pengujian parameter pada model Cox extended menggunakan uji Wald, (4) perbandingan nilai AIC untuk mengetahui model regresi terbaik, dan (5) interpretasi hazard ratio untuk mengetahui adanya peningkatan atau penurunan risiko pada perlakuan tertentu.

Pada penerapan data survival berhenti bekerja diperoleh model Cox extended dengan $g(t)=t$ sebagai model terbaik dengan variabel yang berpengaruh signifikan, yaitu variabel umur, status pernikahan, umur terikat waktu dan status pernikahan terikat waktu.

Pengembangan untuk penelitian selanjutnya mengenai model Cox extended untuk mengatasi nonproportional hazard pada kejadian bersama dapat dilakukan dengan pendekatan lain, yaitu metode Exact dan dapat diterapkan pada kasus berhenti bekerja di Indonesia.

\section{Pustaka}

Agnesia Berlian Nirwana Sari. 2014. Perbandingan Model Regresi Cox Menggunakan Time-Dependent Variable dan Stratified Proportional Hazard untuk Mengatasi Nonproportional Hazard. Jurnal Statistik FMIPA Universitas Brawijaya 2(1): 69-72.

Ata, N., \& Sozer, M. Tekin. 2007. Cox Regression Model with Nonproportional Hazard Applied to Lung Cancer Survival Data. Hacettepe Journal of Mathematics and Statistics 36(2): 157-167.

Blossfeld, Hanz-Peter, \& Rohwer, Gotz. 2002. Techniques of Event History Modeling: New Approaches to Casual Analysis Second Edition. New Jersey: Lawrence Erlbaum Associates, Inc.

Breslow, N. 1974. Covariance Analysis of Censored Survival Data. Biometrics 30:89-99.

Collett, D. 2003. Modelling Survival Data in Medical Research Second Edition. London: Chapman and Hall.

Kleinbaum, D. G., \& Klein, M. 2012. Survival Analysis A Self-Learning Text Third Edition. New York: Springer Science+Business Media, Inc.

Kreitner, Robert, \& Kinicki, Angelo. 2003. Perilaku Organisasi Edisi Pertama. Jakarta: Salemba Empat.

Lee, Elisa T., \& Wang, John Wenyu. 
2003. Statistical Methods for Survival Data Analysis Third Edition. New Jersey: A John Wiley $\&$ Sons, Inc., Publication.

Robbins, Stephen P. \& Judge, Timothy A. 2012. Perilaku Organisasi. Jakarta: Salemba Empat.

Therneau, Terry M. \& Grambsch, Patricia M. 2000. Modeling Survival Data: Extending The Cox Model. New York: Springer-Verlag, Inc.

Xin, Xin. 2011. A Study of Ties and Time-Varying Covariates in Cox Proportional Hazards Model. Tesis. The University of Guelph. 